\title{
EDITORIAL
}

\section{Measuring left ventricular volume and ejection fraction with the biplane Simpson's method}

\section{J E Otterstad}

Are there still problems with two dimensional echocardiographic measurements of left ventricular volume and ejection fraction with the biplane Simpson's method?

Correspondence to: Dr Jan Erik Otterstad, Division of Cardiology, Central Hospital of Vestfold, N-3116 Toensberg, Norway; j-otte@online.no n this issue of Heart, Nijland and colleagues address the important question on how low dose dobutamine echocardiography at an early stage can predict later improvement in left ventricular ejection fraction (LVEF) after an acute myocardial infarction (AMI). ${ }^{1} \mathrm{~A} \geqslant 5 \%$ increase in LVEF was arbitrarily chosen to represent an improvement, and they found this to occur in 21 $(20 \%)$ of 107 patients with AMI. If dobutamine echocardiography revealed myocardial viability in $\geqslant 2$ segments, the prediction of an increase in LVEF had a sensitivity of $81 \%$ and a specificity of $65 \%$. Other predictors for such an improvement were non-Q wave infarction and anterior infarction, but myocardial viability assessed with the stress echo method was the single best predictor of improvement in LVEF.

This study raises some important principal questions related to the echocardiographic methodology in assessing left ventricular volumes and ejection fraction. If the true prognostic value of stress echo post-AMI is to be assessed, one must be convinced that those with an apparent increase in LVEF had a true improvement. This focuses on the degree of reproducibility of the echocardiographic measurements after three months. The authors report that their intra- and interobserver variability in assessment of LVEF with the biplane Simpson's method is $3.4 \%$ and $4.1 \%$, respectively. But they do not report if this excellent reproducibility is related to repeated tracings of the same video recordings or to repeated echocardiographic examinations with an interval similar to that applied in their study. In our own reproducibility study the greatest source of variability was repeated echo examinations and not repeated tracings of video recordings. ${ }^{2}$ Incorporating these two factors with addition of the interobserver variability of repeated videotracings, we assessed that a true, one sided increase of LVEF (with a Za value of 1.28) was $8.5 \%$ and not $5 \%$ as applied in the study of Nijland and in other studies. ${ }^{3}{ }^{4}$ Therefore, we are left with a question of the validity of an increase in LVEF in the 21 patients studied. Scrutinising fig 2 in the paper by Nijland and colleagues, ${ }^{1}$ only eight patients had an LVEF increase of $8.5 \%$ or more. It may well be possible that the remaining 13 patients, or $62 \%$ of those with an increase, also had a true increase. But this should preferably have been verified by reproducibility data from repeated examinations showing that an increase of $\geqslant 5 \%$ was beyond the error connected with the variability of the method.

\section{LONG TERM PROGNOSIS}

This study is too small to verify if the increase in LVEF observed is related to an improved long term prognosis. Most patients in the study population appeared to have a more or less preserved left ventricular systolic function, with a mean (SD) baseline LVEF of 49 (8)\% among those without subsequent improvement and 48 (7)\% among those who improved. Baseline LVEF itself, however, does not appear to be a risk factor for subsequent cardiac events in post-AMI patients with LVEF $\geqslant 40 \%{ }^{5}{ }^{6}$

The study by Nijland and colleagues ${ }^{1}$ raises the interesting question as to whether those with a more or less preserved left ventricular systolic function may have a more favourable course if LVEF has increased significantly after three months. In the recently published LEVEREM study, ${ }^{6}$ we could show that in post-AMI patients with LVEF $\geqslant 40 \%$, an individual decrease in LVEF as well as an increase in left ventricular volumes after three months had a negative prognostic impact on cardiac events in the subsequent 21 months. This study did not, however, evaluate whether those with an increase in LVEF had a better prognosis when compared with patients who had no change in LVEF. Therefore, the prognostic impact of an increase in LVEF as suggested by Nijland and colleagues ${ }^{1}$ should be clarified in larger follow up studies on patients with a preserved left ventricular systolic function post-AMI.

A problem with the biplane Simpson method is so-called "foreshortening" (R Devereux, M St John Sutton, T Plappert, personal communications). The left ventricular volume indices in the studied patient population of Nijland and colleagues ${ }^{1}$ were $63 \mathrm{ml} / \mathrm{m}^{2}$ in diastole and $33 \mathrm{ml} / \mathrm{m}^{2}$ in systole, and thus somewhat larger that in the CATS ${ }^{7}$ and CONSENSUS II echo substudy. Even so, the average stroke volume index in the study group of Nijland and colleagues was $30 \mathrm{ml} / \mathrm{m}^{2}$. This seems to be remarkably low when most patients appeared to have a preserved left ventricular systolic function.

Abbreviations: AMI, acute myocardial infarction; CATS captopril and thrombolysis study; CONSENSUS, cooperative North Scandinavian enalapril survival study; DEFIANT, doppler flow and echocardiography in functional cardiac insufficiency: assessment of nisoldipine therapy; LEVEREM, left ventricular remodelling; LVEF, left ventricular ejection fraction 


\section{LARGER LEFT VENTRICULAR VOLUMES}

In our own experience, post-AMI patients of this category have much larger left ventricular volumes. In the DEFIANT II substudy on the difference between biplane and monoplane left ventricular volume measurements, ${ }^{9}$ mean left ventricular end diastolic volume was $190 \mathrm{ml}$ and mean left ventricular end systolic volume $118 \mathrm{ml}$ with the biplane method. These patients were without overt heart failure and had LVEF between $25-50 \%$ post-AMI. Their mean left ventricular stroke volume was thus $72 \mathrm{ml}$. In the LEVEREM trial the respective mean LV volumes were $164 \mathrm{ml}$ in end diastole and $87 \mathrm{ml}$ in end systole. The mean left ventricular stroke volume was $77 \mathrm{ml}$, and thus similar to what was found in the DEFIANT 2 study. Different patient selection may possibly explain why left ventricular volumes in DEFIANT 2 and LEVEREM are so much greater than in the study of Nijland and colleagues. ${ }^{1}$ Another explanation may be different degrees of "foreshortening" and/or discrepancies in how to perform the correct tracings of the left ventricular endocardium.

It is valuable that Nijland and colleagues ${ }^{1}$ have addressed the question of how to predict later development of LVEF in post-AMI patients. But the study may initiate an interesting debate on how to define correct criteria for a true increase (or even decrease) in left ventricular volumes and ejection fraction after AMI. Furthermore, there may be different "schools" in how to assess left ventricular volumes with the Simpson's biplane technique. With these considerations in mind, it might be a challenge for the working group on echocardiography of the European Society of Cardiology to conduct a consensus document on how to perform these measurements as uniformly and correctly as possible. Such a document may also address the important issue of how to assess true changes in left ventricular volumes and ejection beyond the variability of the biplane
Simpson's method, which now seems to represent a "golden standard" for these measurements.

\section{REFERENCES}

1 Nijland F, Kamp O, Verhorst PM, et al. Early prediction of improvement in ejection fraction after myocardial infarction using low dose dobutamine echocardiography. Heart 2002;88:592-6.

2 Otterstad JE, Froeland G, St John Sutton MG, et al. Accuracy and reproducibility of biplane two-dimensional echocardiographic measurements in left ventricular dimensions and function. Eur Heart 1997:18:507-13.

3 Cintron G, Johnson G, Francis G, et al for the V-Heft VA Coopoerative Studies Group. Prognostic significance of serial changes in left ventricular ejection fraction in patients with congestive heart failure. Circulation 1993;87(suppl VI):VI-17-23.

4 Cornel JH, Bax JJ, Elhendy A, et al. Biphasic response to dobutamine predicts improvement of global left ventricular function after surgical revascularization in patients with stable coronary artery disease. Implications of time course of recovery on diagnostic accuracy. J Am Coll Cardiol 1998:31:1001-10.

5 Multicenter Postinfarction Research Group. Risk stratification and survival after myocardial infarction. N Engl J Med 1983;309:331-6.

6 Otterstad JE, St. John Sutton MG, Froeland GS, et al. Prognostic value of two-dimensional echocardiography and $\mathrm{N}$-terminal proatrial natriuretic peptide following an acute myocardial infarction. Assessment of baseline values (2-7 days) and changes at 3 months in patients with a preserved systolic function. Eur Heart J 2002;23:101 1-20.

7 Van Gilst WH, Kingma JH, Peels $\mathrm{CH}$, et al. Acute intervention with captopril during thrombolysis in patients with first anterior myocardial infarction. Results from the captopril and thrombolysis study (CATS). Eur Heart J 1994; 15:898-907.

8 Bonarjee VVS, Carstensen S, Caidahl K, et al on behalf of the CONSENSUS II multi-echo substudy. Am J Cardiol 1993:72:1004-9.

9 St John Sutton M, Otterstad JE, Plappert T, et al. Quantitation of left ventricular volumes and ejection fraction in post-infarction patients from biplane and single plane two-dimensional echocardiograms. Eur Heart J 1998; 19:808-16.

\section{IMAGES IN CARDIOLOGY}

\section{An unusual cause of mixed mitral valve disease}

$A^{3}$ 38 year old man presented with orthopnoea, palpitation, and paroxysmal nocturnal dyspnoea. Clinical examination revealed features of pulmonary oedema and mixed mitral valve disease as evidenced by the presence of a mid diastolic and ejection systolic murmur in the mitral area. Transthoracic echocardiogram showed a $2.4 \mathrm{~cm}$ spherical, mobile mass within the left ventricular cavity distorting the mitral valve and obstructing its orifice, causing mixed mitral valve disease. At operation, after establishing cardiopulmonary bypass, the left ventricular tumour was approached through the left atrium via a paraseptal approach. A $2.4 \mathrm{~cm}$ encapsulated, spherical tumour attached to the anterior papillary muscle by a broad pedicle was found obstructing the mitral valve orifice. It caused significant mitral stenosis and distorted the alignment of the mitral valve leaflets, preventing leaflet apposition and consequential mitral regurgitation

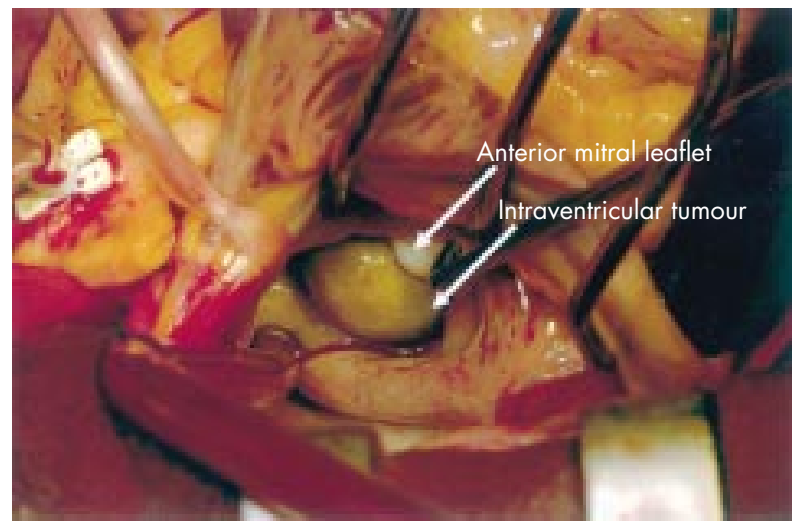

(below left). The pedunculated tumour was mobilised into the left atrium and the pedicle divided from its attachment (below right). Repeat echocardiography showed a normal functioning mitral valve apparatus. Histological analysis revealed that this tumour was an endocardial haemangioma. Immunohistochemistry for factor 8 and CD34 were positive, confirming the haemangiomatous component in the tissue.

This is an interesting case of left ventricular haemangioma mimicking mixed mitral valve disease.

K S Nair

D R Lawrence

P L C Smith s.rhind-tutt@ic.ac.uk

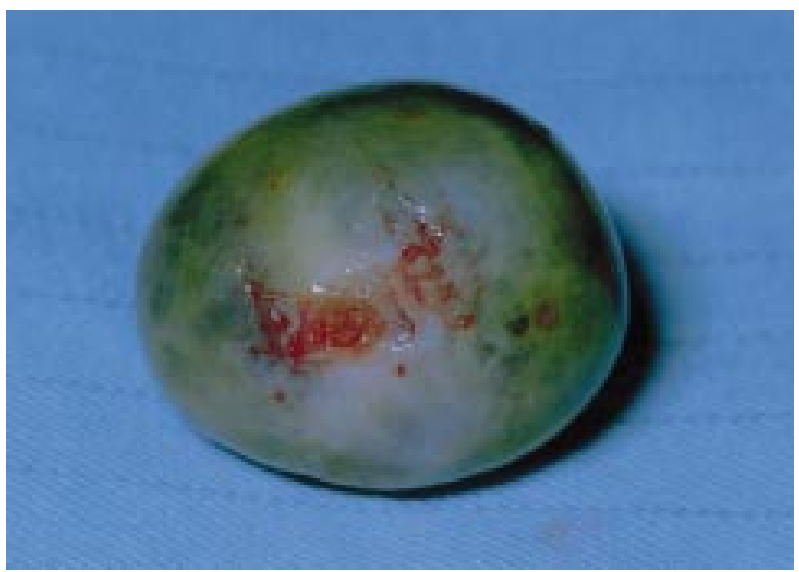

